\title{
Study of Necessities and Technologies for Using Hybrid Photovoltaic-Wind Power Systems
}

\author{
Sobhan Dorahaki \\ Young Researchers and Elite Club, \\ Bushehr Branch, Islamic Azad University, Bushehr, Iran \\ email: sobhandorahaki@gmail.com
}

\begin{abstract}
In recent years, increase in environment concerns and demand for energy are two main issues in ongoing growth of using solar systems. Solar energy has been known as a renewable and clean energy source. One of the most applied and new ways for using sun energy is hybrid photovoltaic technology. This paper discusses requirements, methods, limitations and technologies used in the hybrid photovoltaicwind power system.
\end{abstract}

Keywords: Photovoltaic-Turbine-Wind-Irradiance-Hybrid

Copyright () 2015 Institute of Advanced Engineering and Science. All rights reserved.

\section{Introduction}

Today, studies and researches have increased to find a new fuel for producing electricity, regarding environmental concerns in energy field and decreasing fossil fuel resources. Man has used sun energy during history in various forms like concentrating it in a certain point or its lighting energy.

Most renewable fuel power plants like wind, biomass and solar plants usually feed loads isolated from grid to remote areas [1-4]. For remote areas in power system with low power consumption, renewable energies like photovoltaic system play very effective role.

One issue that makes using solar systems more important and interesting is lack of damage to environment and being free. It can be said that increase in productivity factor and reducing running costs of these systems are two important and promising factors in widespread use of this energy in world [5]. Unfortunately, lack of growth and development of photovoltaic systems increases the cost of photovoltaic systems such that most researchers did not consider using it instead of common energies as cost-effective [6].

Energy loss in the panels have significant role in the efficiency of electric output of panels. Climate can have significant effect on the efficiency of system such that this effect is imposed through radiation, temperature and shadow of a cloud on the area [7].

In order to increase gain of hybrid photovoltaic-wind systems, we need comprehensive and theoretical knowledge. In this regard, researchers have suggested following maximal power point to increase efficiency of system. Researchers have focused on changing panel cells.

One of suggested methods for increase in gain of renewable energies is simultaneous use of solar energy along with other renewable energies [8]. This study presents methods, algorithms and other issues needed for hybrid photovoltaic-wind systems.

\section{Photovoltaic Concept and Modeling Photovoltaic System}

Semiconductor device that transforms sunlight to electricity is known as photovoltaic cell. This phenomenon is called photovoltaic. In order to increase system production voltage, solar cells are placed in series and parallel way. In order to increase voltage and current and produced power by solar arrays through radiation, temperature and other factors like wind can be changed [9-12]. Solar cell is a non-linear element and it can be modelled like current flow as in Figure 1. In Figure 1, $I_{d}$ current is the diode saturation current and $R_{c}$ and Rsh resistances are series and parallel resistances of solar cell. Rsh resistance is larger than $R_{z}$ resistance such that it is ignored in the analysis of solar cells. Solar array forms by placing solar cells near each 
other and its reason is increase in panel's current and voltage. Current equation of solar array based on voltage is as Equation (1):

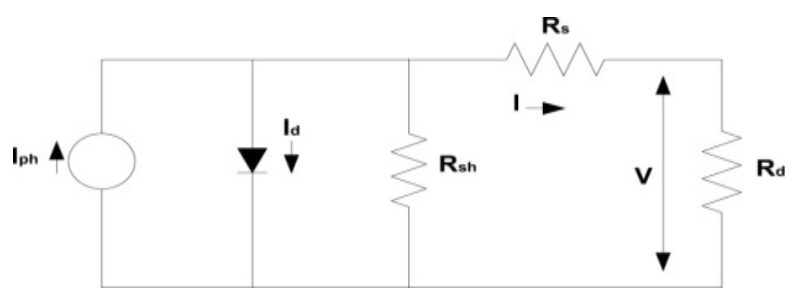

Figure 1. Photovoltaic Cell Model [9]

Current equation of solar array based on voltage is as Equation (1):

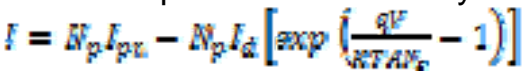

In equation (1), I is panel current, $\mathrm{Np}$ and Ns are series and parallel cells. $\mathrm{q}$ is electron charge and $\mathrm{k}$ is Boltzmann constant. $\mathrm{A}$ is ideal factor [13]. In equation (1), Id is reverse saturated current. Id calculates as equation (2) [14]:

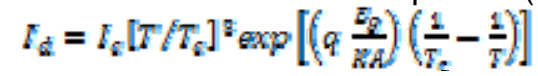

In equation 2, $T_{\varepsilon}$ is cell reference temperature. $I_{\varepsilon}$ is saturated current in $T_{\varepsilon}$ temperature. $\mathrm{T}$ is cell temperature and $E_{g}$ is the gap between two bands which is different for each semiconductor used in solar cell. $I_{p h}$ is called current produced by cell which depends on radiation and temperature of cell. $I_{p h}$ obtains by equation (3).

$$
I_{p \bar{s}}=\left[I_{s a r}+K_{q}\left(T-T_{\varepsilon}\right)\right][S / 100]
$$

In equation (3), $I_{s c r}$ is short-circuit in reference temperature. $K_{i}$ is the temperature factor. It is clear that if we want to obtain $\nabla_{\max }, V$ should be multiplied in the equation (2) and then, we calculate $\mathrm{dp} / \mathrm{dv}=0$.

\section{Producing Energy using Wind}

Feed induction generator is, in fact, winding rotor generator that its stator is directly connected to the power network and its rotor is connected through two consecutive electric converters [15]. Figure 2 shows it schematically.

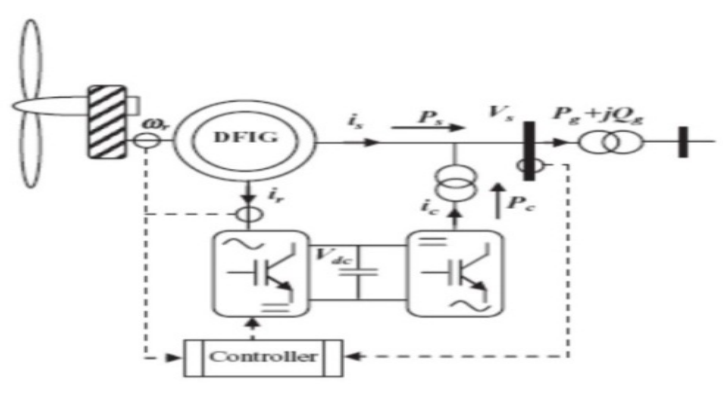

Figure 2. Wind Turbine Generator Schematic

Equation (4) and (5) might be utilized to simulate a Part of aerodynamic wind turbine [15]:

$$
\begin{aligned}
& P_{m}=\frac{1}{2} \pi \rho R^{2} C_{k}(\lambda \beta) F^{3} \\
& \lambda=\frac{\pi \omega_{r}}{7}
\end{aligned}
$$


Equations 6-12 simulate Parts of Gearbox and DFIG generator.

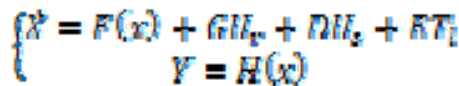

$$
\begin{aligned}
& X=\left[I_{\mathrm{rQ}} I_{\mathrm{sd}} I_{\mathrm{rQ}} I_{\mathrm{rd}} \omega_{\mathrm{rq}}\right] \\
& T_{l}=\frac{T_{\text {mins }}}{K^{2} \text { gers }}
\end{aligned}
$$

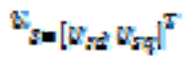

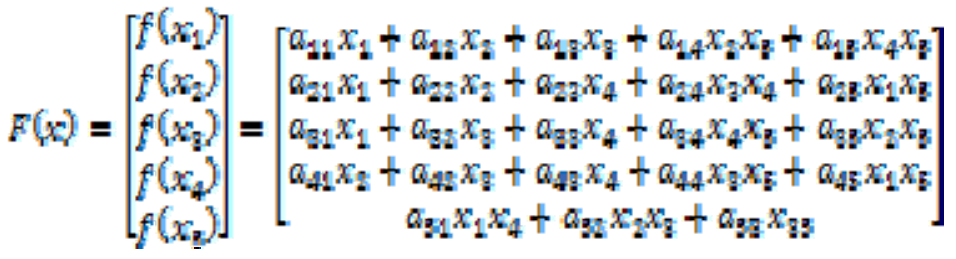

$$
\begin{aligned}
& A=\left[\begin{array}{ccccc}
-\frac{R_{s}}{L_{s}} K & \left(\frac{2 M^{2} \pi f}{L_{s} L_{r}}-2 \pi f\right) k & \frac{M R_{r}}{L_{s} L_{r}} k & \frac{P M^{2}}{2 L_{s} L_{r}} & -\frac{P M}{2 L_{s}} \\
-\left(\frac{2 M^{2} \pi f}{L_{s} L_{r}}-2 \pi f\right) k & -\frac{R_{s}}{L_{s}} K & \frac{M R_{r}}{L_{s} L_{r}} k & \frac{P M}{2 L_{s}} & \frac{P M^{2}}{2 L_{s} L_{r}} \\
\frac{M R_{s}}{L_{s} L_{r}} k & -\frac{R_{r}}{L_{r}} K & \left(\frac{2 M^{2} \pi f}{L_{s} L_{r}}-2 \pi f\right) k & \frac{p}{2} k & \frac{P M}{2 L_{r}} k \\
\frac{M R_{s}}{L_{s} L_{r}} k & -\left(\frac{2 M^{2} \pi f}{L_{s} L_{r}}-2 \pi f\right) k & -\frac{R_{r}}{L_{r}} K & \frac{p}{2} k & -\frac{P M}{2 L_{r}} k \\
\frac{3 p}{4 J} & -\frac{3 p}{4 J} & -\frac{B}{J} & \frac{1}{J} & 0
\end{array}\right]
\end{aligned}
$$

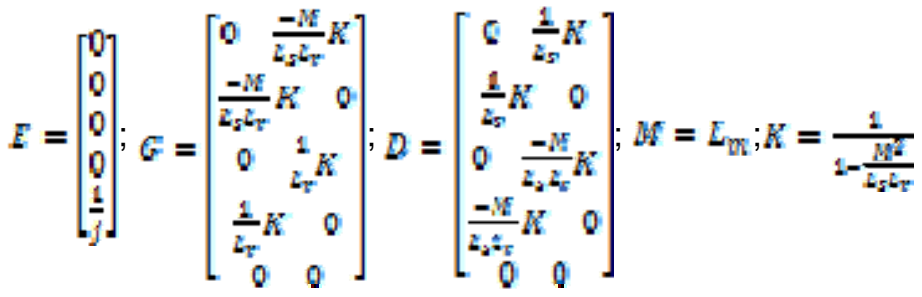

Among advantages of using synchronous generators, we can refer to following:

1) As a result of constant frequency of network and regulating rotor frequency, there is possibility of controlling mechanical velocity and absorbing maximum power from wind turbines.

2) Nominal power of electronic converters in double induced generator is very lower than nominal power used in synchronous generators.

\begin{tabular}{|c|c|}
\hline Variable & Definition \\
\hline$P_{m}$ & Kinetic energy of the rotor \\
\hline$\rho$ & Air density \\
\hline Swept area of the rotor & $\mathrm{R}$ \\
\hline $\mathrm{V}$ & Wind speed \\
\hline$C_{p}(A, B)$ & Power factor \\
\hline$\lambda$ & Tip speed ratio \\
\hline$\omega_{t}$ & Angular velocity of the turbine \\
\hline$L_{x}$ & Rotor inductance \\
\hline $\overrightarrow{\mathrm{I}_{g}}$ & Stator inductance \\
\hline$T_{l}$ & Aerodynamic generator torque \\
\hline$T_{\text {wrr }}$ & Torque of the turbine \\
\hline$E_{\text {gear }}$ & Conversion ratio gearbox \\
\hline
\end{tabular}

Table 1. Variables used in equations 4-12 
Regarding non-linearity of wind turbine curves and using gain table, various studies have been done for achieving more power. The parameters exploited in Equations (4-12) are presented in Table 1.

\section{Hybrid Photovoltaic-Wind Power Systems and Necessity of using them}

In recent decade, various studies have conducted on this subject. Generally, it can be said that synchronous use of renewable energy along with thermal and wind energies and other renewable fuels, connected or disconnected from grid, is called hybrid. Some researchers believe that using photovoltaic system and sunlight is not suitable. One of their reasons is the weakness of this system in some climates in some hours which necessitate synchronous using of different energies. Generally, among advantages of this systems, we can refer to increase in the stability of network, reduction in outage and increasing reliability of network [16-20]. This study has investigated the climate changes (effective factors on hybrid system) in Bushehr in Iran. Figure 3 shows the radiation changes for one month in Bushehr. As figure 3 shows, changes in radiation in one month is great. Figure 4 shows the amount of changing wind power in one month in Bushehr. Regarding extensive changes in radiation and wind in diagrams 3 and 4 in one month, we can say that using these two energies along with each other in hybrid form is a logical work because non-implementation of it leads to energy shortage in days with low radiation or low wind velocity

One of the system problems is the unpredictable behavior of these systems from output view. Wind and photovoltaic hybrid depends on the climate of region. Among these influential factors, we can refer to radiation, temperature and wind velocity [9]. Connection schematic of this arrangement is as figure 4 . In figure 3, photovoltaic panel is connected directly to hybrid controller. Energy produced by these panels is connected indirectly from controller charge to hybrid controller. Generally, hybrid controller is known as a sample larger than controller charge such that this device has the role of controlling system. It is clear that Ac and Dc loads can be embedded in this system.

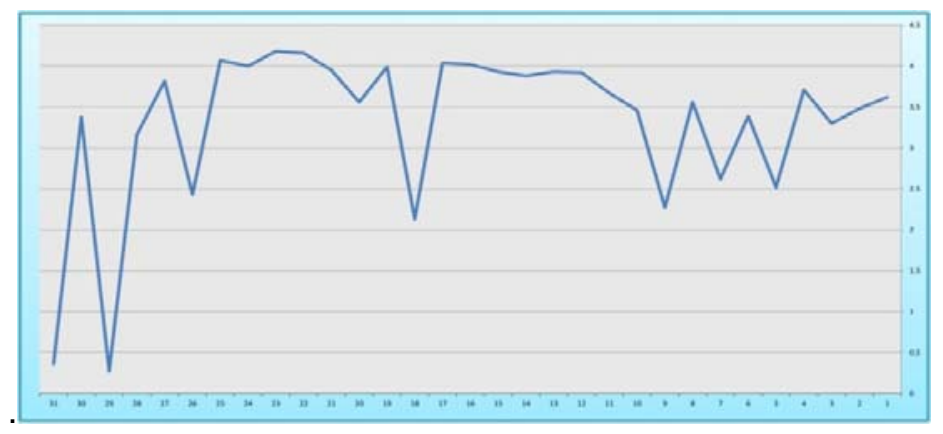

Figure 3. Radiation Changes for One Month In Bushehr [21]

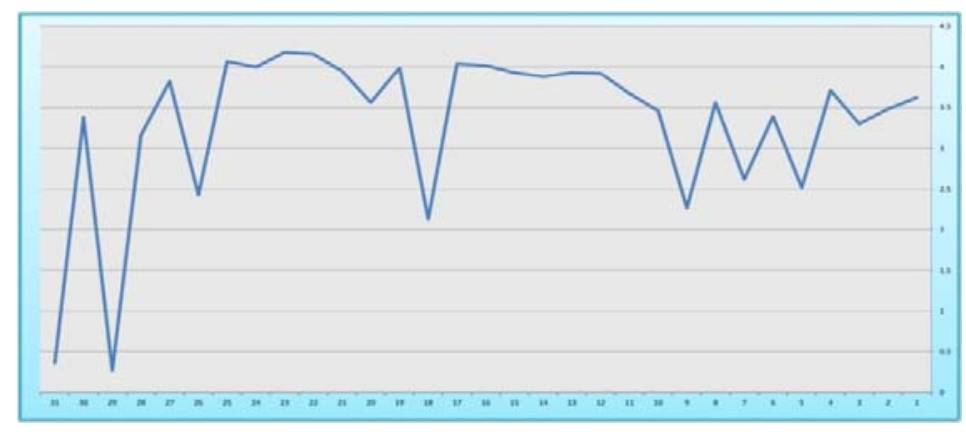

Figure 4. Wind Velocity Based on $\mathrm{m} / \mathrm{s}$ in One Month in Bushehr [21]

TELKOMNIKA Vol. 16, No. 1, October 2015: 7 - 12 


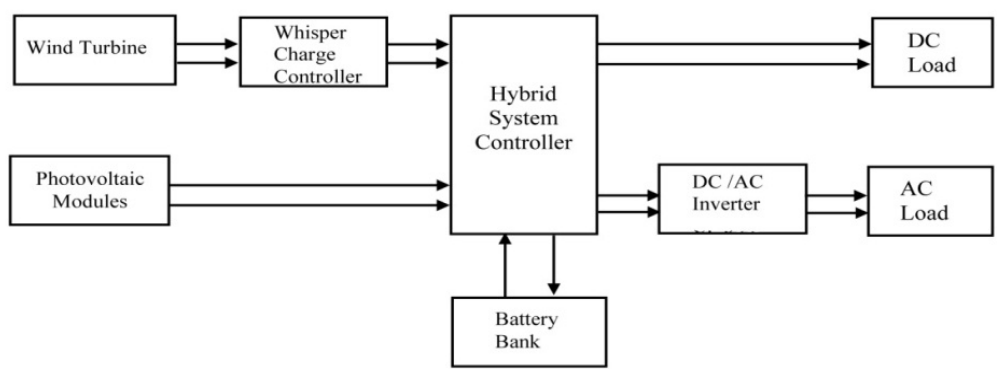

Figure 5. Schematic of Connecting Hybrid Photovoltaic-Wind System [22]

Among important and influential advantages of these systems is that wind and photovoltaic solar systems can act to supplement each other and make the network stable. At night or when the sky is windy, wind system can continue its works and helps photovoltaic system. Photovoltaic panel in wind reducing hours will impose its effect on the efficiency of system.

\section{Conclusion}

By reducing resources of fossil fuels and increasing environment pollutions, it is inevitable to move toward renewable and clean energies. In this regard, by considering relations studied in this paper, wind velocity and radiation amount are two essential factors that using one of photovoltaic and wind systems leads to problem. Regarding figures 3 and 4, wind and radiation has great changes during one month which shows necessity of using solar-wind systems. In this study, connection of solar hybrid system and necessity of using solar hybrid system was studied. It is suggested that future studies leads to increase in the efficiency of wind-hybrid systems using power maximizing systems.

\section{References}

[1] M Canale, et al. A revolution in wind energy generation. Energy. 2008; 34(3): 355-361.

[2] SA Kalogirou. The potential of solar industrial process heat applications. Energy. 2003; 76(4): 337361.

[3] W Tien, KC Kuo. An analysis of power generation from municipal solid waste (MSW) incineration plants in Taiwan. Energy. 2010; 35(12): 4824-4830.

[4] JF Mercure. Salas PAn assessment of global energy resource economic potentia. Energy. 2012; 46(2): 322-326. Doi: 10.1016/j.energy.2012.08.018.

[5] Solar energy perspectives: executive summary. International Energy Agency; 2011.

[6] D Coiante, L Barra. Can photovoltaics become an effective energy option. Solar Energy Materials and Solar Cells. 1992; 27(1): 7989.

[7] S Dorahaki. Evaluating the Radiation and Temperature Effect on Photovoltaic Systems. Bulletin of Electrical Engineering and Informatics. 2015; 4(1): 1-6.

[8] WT Chong, et al. Techno-economic analysis of a wind-solar hybrid renewable energy system with rainwater collection feature for urban high-rise application. Energy. 2011; 88: 4067-4077.

[9] A Rezaei, et al. Investigating The Effect Of Environmental Factors On The Performanee Of Solar Arrays (A Case Study Of Shiraz City). Indian journal of fundamental and applied life science. 2014; 4(1): 1729-1734.

[10] A Jusoh, et al. A Review on Favourable Maximum Power Point Tracking Systems in Solar Energy Application. TELKOMNIKA Telecommunication, Computing, Electronics and Control. 2014; 12(1): 622.

[11] S Dorahaki. A Survey on Maximum Power Point Tracking Methods in Photovoltaic Power Systems. Bulletin of Electrical Engineering and Informatics. 2015; 4(3).

[12] Awang Bin Jusoh, et al. Variable Step Size Perturb and Observe MPPT for PV Solar Applications. TELKOMNIKA Telecommunication, Computing, Electronics and Control. 2015; 13(1): 1- 12.

[13] MA Khallat, S Rahman. A probabilistic approach to photovoltaic generator performance prediction. IEEE Transactions on Energy Conversion. 1986; EC-1(3): 34-40.

[14] G Vachtsevanos, K Kalaitzakis. A hybrid photovoltaic simulator for utility interactive studies. IEEE Transactions on Energy Conversion. 1987; EC-2(2): 227-231.

[15] T Ackermann. Wind Power in Power System. John Wiley \& Sons, England. 2005. 
[16] SK Nandi, HR Ghosh. A wind-PV-battery hybrid power system at Sitakunda in Bangladesh. Energy Policy. 2009; 37(9): 3659-3664.

[17] O Ekren, et al. Break-even analysis and size optimization of a PV/wind hybrid energy conversion system with battery storage-A case study. Energy. 2009; 86(7-8): 1043-1054.

[18] T Markvart. Sizing of hybrid photovoltaic-wind energy systems. Solar Energy. 1996; 51(4): 277-281.

[19] H Shahinzadeh, et al. Design and Economic Study for Use the Photovoltaic Systems for Electricity Supply in Isfahan Museum Park. International Journal of Power Electronics and Drive Systems (IJPEDS). 2013; 3(1): 83-94.

[20] H Shahinzadeh, et al. Optimal Planning of an Off-grid Electricity Generation with Renewable Energy Resources using the HOMER Software. International Journal of Power Electronics and Drive Systems (IJPEDS). 2005; 6(1).

[21] RETScreen software, Version 4.0.0, designed by Canadian Government for calculations related to Renewable Energies connected to NASA database.

[22] R Maouedja, et al. Performance evaluation of hybrid Photovoltaic-Wind power systems. 2014; 50: 797-807. 